\title{
Chemical Oxygen Demand (COD) Attenuation of Methyl Red in Water using Biocarbons obtained from Nipa Palm Leaves
}

\author{
*11PEREWARE ADOWEI; A. A. ABIA
}

\author{
Department of Pure \& Industrial Chemistry, Faculty of Science, University of Port Harcourt, P. M. B. 5323, Port Harcourt, Nigeria,
} *Corresponding author: pere.adowei@yahoo.com

\begin{abstract}
Attenuation of methyl red dyestuff in water was assessed by COD reduction after contacting the solution with biocarbons produced by one-pot pyrolysis of sopping Nipa palm leaf biomass in $\mathrm{H}_{2} \mathrm{O}$ (physically-modified biocarbon: $\mathrm{PMB}), \quad \mathrm{H}_{3} \mathrm{PO}_{4}$ (acid-modified biocarbon: AMB) and $\mathrm{KOH}$ (base-modified biocarbon: BMB). Physicochemical characterization of the biocarbons were investigated and the result for BMB were carbon yield $(46.6 \pm 0.21 \%)$, porosity (79\%), iodine number $(814 \mathrm{mg} / \mathrm{g})$, surface area $\left(681 \mathrm{~m}^{2} / \mathrm{g}\right)$ and $\mathrm{pH}(6.41 \pm 0.11$ to $7.81 \pm 0.12)$. Optimal COD reduction for methyl red in water by PMB, AMB, BMB compared with CAC were $82.7 \%, 76.7 \%, 83.5 \%$, and $93.3 \%$ respectively. Langmuir isotherm model was used to predict the maximum COD reduction capacity of the biocarbons and CAC (PMB: $2.15 \mathrm{mg} / \mathrm{g}$, AMB: $8.73 \mathrm{mg} / \mathrm{g}$, BMB: $11.83 \mathrm{mg} / \mathrm{g}$ and CAC: $62.60 \mathrm{mg} / \mathrm{g})$. Thermodynamic assessment of the data based on Gibb's free energy $\left(\Delta \mathrm{G}^{\circ}\right)$ revealed that $\Delta \mathrm{G}^{\circ}$ values were negative $(-1.31$ to $-5.89 \mathrm{~kJ} / \mathrm{mol})$ and relatively low $(<<-20$ $\mathrm{kJ} / \mathrm{mol}$ ), which indicated spontaneous nature requiring minimal energy. One-way analysis of variance (ANOVA) performed to validate the COD degradation capacity for methyl red in water amongst the biocarbons revealed no significant difference ( $p>0.05$ ). Conclusively, Nipa palm could be a favorable source to derive eco-friendly and locally accessible biocarbon for mitigation of organic contaminants in water. CJASEM

http://dx.doi.org/10.4314/jasem.v20i4.33
\end{abstract}

Keywords: Chemical oxygen demand, biocarbon, methyl red, biodegradation, bioremediation, Nipa palm

Attenuation of chemical oxygen demand (COD) as index of measurement to evaluate the degree of organic contaminant elimination in water is a low cost and viable option for low developing countries. This is because COD measurement is fast, reliable, accurate and simple in the face of expensive modern instrumentation.

Contamination of water resources by dye pollutants such as methyl red has serious environmental implications, due to their toxicity, high COD, and nasty appearance. Therefore, releasing such contaminants into the aquatic ecosystem without competent management is unwelcomed (Adowei et al., 2015, Abechi et al., 2013, Tarawou et al., 2010, Horsfall et al., 2007, Birhanli and Ozmen 2005).

Clothing and paper industries produce wastewater with numerous constituents that contains large amount of dyes, which may be difficult to treat (O'Neill et al., 2000). Conventional methods of treating dye laden wastewater which includes biological oxidation, chemical oxidation, photo-degradation, coagulation and reverse osmosis are expensive (Ekpete and Horsfall, 2011, Ekpete et al., 2011, Tsai et al., 2001). However, in recent times, an extensive diversity of low priced materials has been employed. They include agricultural by-product such as waste coir pith (Kadirvelu et al., 2000), Indian rosewood sawdust (Namasivayam et al., 2001), Fluted Pumpkin Wastes (Horsfall and Spiff 2005, Ekpete and Horsfall, 2011, Ekpete et al., 2011a, Ekpete et al., 2011b), Rhizophora mangle Aerial Root Waste (Horsfall et al., 2005), almond tree leaves waste
(Horsfall and Vicente, 2007), Wild Cocoyam Biomass (Horsfall and Spiff, 2005) Cassava Waste Biomass (Horsfall and Abia, 2003) However, these biomaterials do not have the capacity to withstand the harshness of wastewater and many researchers have turned to converting the biomaterials into activated carbon as alternative low cost materials (Ahmad et al., 2010, Tarawou et al., 2010a,b,c, Ahmad and Hameed, 2009, Adinata et al., 2007, Ahmedna et al., 2000).

Nipa palm (Nypa Fruiticans Wurmb) belongs to the family Palmae or Arecaceae (Mohamad et al., 2014) that propagates along muddy and especially soft banks of brackish inter-tidal area of rivers. In the Niger Delta area of Nigeria, Nipa palm plant is speedily attacking the mangrove forest and eventually interchanging with the important floral species such as Rhizophora spp. and Avicennia Africana. These two mangrove species offer the indigenous people with fuel-wood, fishing poles, tannin and provide excellent environment for shelter, nurseries and breeding grounds for fish, periwinkles, crabs, oysters and clams. This threat to the important mangrove floral species by Nipa palm is a source of distress because locals depend on these species for their socio-economic wellbeing (Adowei et al., 2014, Wankasi et al., 2005).

Therefore, the aim of this work was to transform leaves of Nipa palm into differentially modified biocarbons via a one-pot pyrolysis and their subsequent use for evaluating COD reduction of methyl red in water. 


\section{MATERIALS AND METHODS}

Sample Collection: Collection of Nipa palm plant was done at the inter-tidal flats of Ogbunabali waterfront in Port Harcourt, Rivers State, Nigeria (Figure 1) with coordinates of $4^{\circ} 49^{\prime} 27^{\prime \prime} \mathrm{N} 7^{\circ} 2^{\prime} 1^{\prime \prime} \mathrm{E}$ and $4.82417^{\circ} \mathrm{N}$ $7.03361^{\circ} \mathrm{E}$ respectively and taken to the herbarium laboratory for taxonomic classification.

Sample Preparation: Fresh Nipa palm fronds were carefully removed from the stalks and washed with sufficient water to remove surface filth and sun dried, followed by oven drying at $110{ }^{\circ} \mathrm{C}$ for several days. Dried leaves were grounded using a grinder (Landa Cisa 2D) to a fine powdered biomass and sieved with mesh size $106 \mu \mathrm{m}$.

List of Chemicals: The major reagents used include: ferrous ammonium sulphate (FAS), ferroin indicator, iron (II) sulphate heptahydrate $\left(\mathrm{FeSO}_{4} \cdot 7 \mathrm{H}_{2} \mathrm{O}\right)$, hydrogen peroxide $\left(\mathrm{H}_{2} \mathrm{O}_{2}: 30 \% \mathrm{~W} / \mathrm{V}\right)$, sulphuric acid $\left(\mathrm{H}_{2} \mathrm{SO}_{4}\right)$, sodium hydroxide $(\mathrm{NaOH})$, acetic acid $\left(\mathrm{CH}_{3} \mathrm{COOH}\right)$, potassium dichromate $\left(\mathrm{K}_{2} \mathrm{Cr}_{2} \mathrm{O}_{7}\right)$, mercuric sulphate $\left(\mathrm{HgSO}_{4}\right)$, silver sulphate $\left(\mathrm{Ag}_{2} \mathrm{SO}_{4}\right)$, manganese oxide $(\mathrm{MgO})$, hydrochloric acid $(\mathrm{HCl}: 10$ $\%)$, potassium hydroxide $(\mathrm{KCl}: 10 \%, 0.9 \mathrm{M})$, phosphoric acid $\left(\mathrm{H}_{3} \mathrm{PO}_{4}: 10 \%, 3.27 \mathrm{M}\right)$, methyl red sodium salt $\left(\mathrm{C}_{15} \mathrm{H}_{14} \mathrm{~N}_{3} \mathrm{NaO}_{2}\right)$ and commercial activated carbon (AquaNucha).

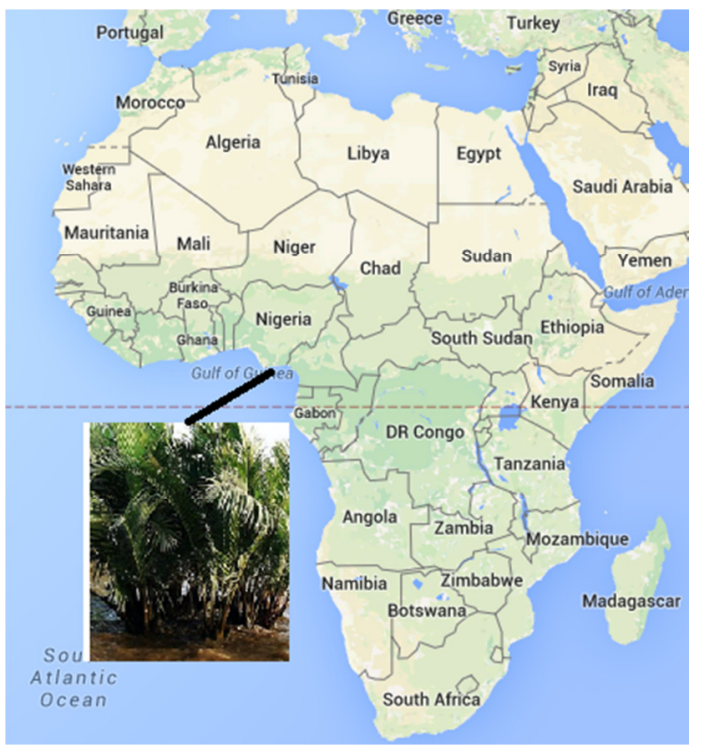

Fig 1: Map of Africa (with Nipa palm insert) collected at Ogbunabali waterfront, Rivers State, Nigeria

Production of Physically Modified Biocarbons Production of physically modified biocarbons has been published elsewhere (Adowei, et al, 2015, Itodo et al., 2009, Turoti et al., 2007, Gimba et al., 2004 and Fan et al., 2003). Briefly, a 1:1 ratio of Nipa palm leaves biomass and water was carefully made. The paste was heated to $500{ }^{\circ} \mathrm{C}$ for $10 \mathrm{~min}$ and left in the oven for 2 $\mathrm{hr}$, and poured into a bowl containing some ice block crystals. Excess water was drained and the paste dried at ambient temperature to give physically modified biocarbon (PMB). To eliminate surface ash and remove residual acid, PMB was thoroughly washed with $10 \%$ $\mathrm{HCl}$ and sufficient hot water, followed by oven drying to constant weight and sieved through $<106 \mu \mathrm{m}$ sieve.

\section{Production of Acid and Base Modified Biocarbons}

Carbonized biocarbon was modified into two sets of biocarbons according to the methods of Ahmedna et al., 2000, Ash et al., 2006 and Sugumaran and Seshadri, 2009,) with slight modifications. The modified biocarbons were (i) Acid modified biocarbon (AMB) and (ii) Base modified biocarbon (BMB). Briefly, AMB and $\mathrm{BMB}$ were made by sopping some Nipa palm leaves biomass in $10 \%(3.27 \mathrm{M}) \mathrm{H}_{3} \mathrm{PO}_{4}$ and $10 \%(0.9$ $\mathrm{M}) \mathrm{KOH}$ solutions respectively with careful mixing to form pastes, which were heated to $500{ }^{\circ} \mathrm{C}$ within 10 min, cooled to room temperature and weighed. The biocarbons formed were thoroughly washed with $10 \%$ $\mathrm{HCl}$ and plenty of hot water (complete washing was achieved at $\mathrm{pH} 7 \pm 0.5)$, followed by oven drying to constant weight and sieved through $<106 \mu \mathrm{m}$ sieve.

Commercial Activated Carbon (CAC): A top woodbased activated carbon with trade name AquaNuchar SA-1500 was purchased and used as the control.

Experimental Procedures for Physicochemical Characterization: Some physicochemical physiognomies which affect biocarbon surface properties were evaluated.

Biocarbon Yield: The percent biocarbon yield was calculated by applying eqn.1 (Cui et al., 2007).

$$
x(\%)=\frac{\mathrm{m}}{\mathrm{m}_{\mathrm{o}}} \times 100 \ldots \ldots \ldots \ldots \ldots \ldots \ldots
$$

Where $x=$ biocarbon yield (\%), $m=$ mass of biocarbon $(\mathrm{g})$ and $m_{o}=$ mass of raw sample $(\mathrm{g})$.

Attrition: Biocarbon attrition was determined by wet attrition method of Toles et al., 2000 with slight modification which has been published elsewhere (Adowei, et al., 2015).

$p H$ : Determination of biocarbon $\mathrm{pH}$ was done by standard method - ASTMD3838-80 (AOAC, 1999) with slight modification which has been published elsewhere (Adowei et al., 2015). 
Ash Content: Evaluating biocarbon ash content was achieved by standard method number ASTM D2866-94 (AOAC, 1999) with slight modification which has been published elsewhere (Adowei, et al., 2015).

Moisture Content: Thermal drying method (Rengaraj et al., 1999) was used for determination of moisture content with slight modification which has been published elsewhere (Adowei et al., 2015).

Iodine Number: Sodium sulphate titration method as reported by Madu and Lajide (20135) was used to determine iodine number of biocarbons with slight modification which has been published elsewhere (Adowei et al., 2015).

Porosity: Biocarbon penetrability was evaluated as given by Aziza et al., (2008) with slight modification.

Surface Area: Sears' method (Sears, 1956) as modified by Alzaydien (2009) was used to measure the surface area of the biocarbons.

Standard Methyl Red Solutions: $1.0 \mathrm{~g}$ water soluble Nasalt of methyl red crystals were weighed to make a stock solution of $1000 \mathrm{mg} / \mathrm{l}$. Working methyl red solutions with concentrations (mg/l) of 20, 40, 60, 80, and 100 were then prepared.

Biocarbon Dosage Determination: 0.2, 0.4, 0.6, 0.8, and $1.0 \mathrm{~g}$ of each biocarbons and CAC were weighed into several $150 \mathrm{ml}$ plastic sample containers followed by addition of $50 \mathrm{ml}$ methyl red $(100 \mathrm{mg} / \mathrm{l})$ solution, covered firmly and agitated for 1 hour at $150 \mathrm{rpm}$, thereafter, the suspensions were allowed to stand on the bench for $30 \mathrm{~min}$, centrifuged at $2000 \mathrm{rpm}$ for $2 \mathrm{~min}$ to obtain clear supernatant solutions for analysis of final $\operatorname{COD}\left(\mathrm{COD}_{\mathrm{f}}\right)$.

Initial Concentration Determination: $2.0 \mathrm{~g}$ of each biocarbons and CAC were weighed into several $150 \mathrm{ml}$ plastic sample containers followed by addition of $50 \mathrm{ml}$ methyl red with the following concentrations $(\mathrm{mg} / \mathrm{l})$ : 20, 40, 60, 80, and 100, covered firmly and agitated for 1 hour at $150 \mathrm{rpm}$. Thereafter, the suspensions were allowed to stand for $30 \mathrm{~min}$, centrifuged at $2000 \mathrm{rpm}(2$ min) to obtain clear supernatant solutions for final COD $\left(\mathrm{COD}_{\mathrm{f}}\right)$ analysis.

Initial pH Determination: $2.0 \mathrm{~g}$ of each biocarbons and CAC were weighed into several $150 \mathrm{ml}$ plastic sample containers followed by addition of $50 \mathrm{ml}$ methyl red with concentration (100 mg/l), covered firmly and agitated for 1 hour at $150 \mathrm{rpm}$. The $\mathrm{pH}$ values of these suspensions were adjusted to 2.0, 3.0, 4.0, 5.0, 6.0, 7.0, 8.0 and 9.0 by adding either conc. $\mathrm{HCl}$ or $\mathrm{NaOH}$. The suspensions were allowed to stand for $30 \mathrm{~min}$, centrifuged at $2000 \mathrm{rpm}$ for $2 \mathrm{~min}$ to obtain clear supernatant solutions for analysis of final COD $\left(\mathrm{COD}_{\mathrm{f}}\right)$.

Reflux Time Determination: $2.0 \mathrm{~g}$ of each biocarbons and CAC were weighed into several $150 \mathrm{ml}$ plastic sample containers followed by addition of $50 \mathrm{ml}$ methyl red solution with concentration $(100 \mathrm{mg} / \mathrm{l})$, covered firmly and agitated for 1 hour at $150 \mathrm{rpm}$. The $\mathrm{pH}$ value of the suspensions were adjusted to 6.0 by adding either conc. $\mathrm{HCl}$ or $\mathrm{NaOH}$. The containers were labelled for different refluxing time interval of 10, 20, 30, 40, 50, 60 minutes. At the end of each time interval, the suspensions were allowed to stand for $30 \mathrm{~min}$, centrifuged at $2000 \mathrm{rpm}$ for $2 \mathrm{~min}$ to obtain clear supernatant solutions for analysis of final COD $\left(\mathrm{COD}_{\mathrm{f}}\right)$.

COD Reduction Determination: The two-step process of Waynes (1997) was adopted to determine the COD reduction of the methyl red solution by biocarbon.

First Step: This is the digestion step where organic matter is oxidized by dichromate ions in sulphuric acid to $\mathrm{CO}_{2}$ and $\mathrm{H}_{2} \mathrm{O}$. During heating the dichromate ions $\left(\mathrm{Cr}_{2} \mathrm{O}_{7}^{-2}\right)$ form orange-colored solutions.

$$
\begin{gathered}
2 \mathrm{C}_{8} \mathrm{H}_{5} \mathrm{O}_{4}(\mathrm{aq})+10 \mathrm{~K}_{2} \mathrm{Cr}_{2} \mathrm{O}_{7}(\mathrm{aq})+40 \mathrm{H}_{2} \mathrm{SO}_{4}(\mathrm{aq}) \rightarrow \\
16 \mathrm{CO}_{2}(\mathrm{~g})+45 \mathrm{H}_{2} \mathrm{O}(\mathrm{l})+10 \mathrm{Cr}_{2}\left(\mathrm{SO}_{4}\right)_{3}(\mathrm{aq})+ \\
10 \mathrm{~K}_{2} \mathrm{SO}_{4}(\mathrm{aq})
\end{gathered}
$$

Second Step: During titration, ferrous ammonium sulphate (FAS) reacts with dichromate ion to form green coloured chromic ion solution. After the end point, FAS reacts with the indicator to form brown colour solution as depicted below.

$$
3 \mathrm{Fe}^{2+}+\mathrm{Cr}^{6+}=3 \mathrm{Fe}^{3+}+\mathrm{Cr}^{3+}
$$

To determine the COD of each sample, $10 \mathrm{ml} 0.125 \mathrm{M}$ $\mathrm{K}_{2} \mathrm{Cr}_{2} \mathrm{O}_{7}$ solution was added to $20 \mathrm{ml}$ clear supernatant solution in $250 \mathrm{ml}$ round-bottom flask followed by addition of $1.0 \mathrm{~g}$ silver sulphate and drop-wise addition of $40 \mathrm{ml}$ conc. sulphuric acid with gentle swirling until complete dissolution of silver sulphate occurs. Antibumping aid were added to the flask and a reflux condenser connected. The mixture was gently refluxed for $10 \mathrm{~min}$ or more as the case may be, after which its content was cooled. $50 \mathrm{ml}$ distilled water was flushed through the condenser, and the cooling completed under running tap water. 2 drops of ferro in indicator solution 
was added and the subsequent mixture titrated with standardized $0.025 \mathrm{M}$ FAS solution until a change in colour from yellow-green via blue-green to reddish brown was observed, which indicated the end-point. 20 $\mathrm{ml}$ distilled water as blank was also taken through the same process.

Analysis of Experimental Data: Quantification of COD Reduction: COD attenuation for the various solutions and blanks were quantified as presented in eqn. 2 .

$$
\text { COD as } \mathrm{mg} \mathrm{O}_{2} / l=\frac{\left(\mathrm{V}_{\mathrm{A}}-\mathrm{V}_{\mathrm{B}}\right) \times \mathrm{m} \times 8000}{\mathrm{~V}_{\mathrm{S}}} \ldots \ldots \ldots \ldots . . .2
$$

Where $\mathrm{V}_{\mathrm{A}}=$ volume of FAS used for blank $(\mathrm{ml}) ; \mathrm{V}_{\mathrm{B}}=$ volume of FAS used for sample $(\mathrm{ml}) ; \mathrm{M}=$ molarity of FAS; $\mathrm{V}_{\mathrm{s}}=$ Volume of sample used $(\mathrm{ml})$ and $8000=$ milli-equivalent weight of oxygen $\mathrm{x} 1000 \mathrm{ml} / l$.

Evaluation of \% COD Reduction: This was calculated after quantifying the COD attenuated for initial and final solutions as presented in Eqn. 3.

$$
\% \text { COD Removed }=\frac{\mathrm{COD}_{\mathrm{i}}-\mathrm{COD}_{\mathrm{f}}}{\mathrm{COD}_{\mathrm{i}}} \times 100 \ldots \ldots \ldots \ldots . . . .3
$$

Where $\mathrm{COD}_{\mathrm{i}}=\mathrm{COD}$ for initial methyl red solutions before interactions with biocarbons $(\mathrm{mg} / l)$ and $\mathrm{COD}_{\mathrm{f}}=$ COD for methyl red solutions after interactions with biocarbons $(\mathrm{mg} / \mathrm{l})$.

Evaluation of COD Reduction Capacity at Equilibrium The apparent capacity of biocarbons and CAC for COD reduction were examined using the relationship expressed in eqn. 4 .

$$
\mathrm{q}_{\mathrm{e}}=\frac{\left(\mathrm{COD}_{\mathrm{i}}-\mathrm{COD}_{\mathrm{f}}\right) \mathrm{V}}{\mathrm{w}} \ldots \ldots \ldots \ldots \ldots \ldots
$$

Where $\mathrm{q}_{\mathrm{e}}=$ COD reduction capacity $(\mathrm{mg} / \mathrm{g})$ of methyl red at equilibrium, $\mathrm{COD}_{\mathrm{i}}=\mathrm{COD}$ for methyl red solution before interaction with biocarbons $\left(\mathrm{mg} \mathrm{O}_{2} / / l\right) \cdot \mathrm{COD}_{\mathrm{f}}=$ COD for methyl red solution after interaction with biocarbons $\left(\mathrm{mg} \mathrm{O}_{2} / l\right) . \mathrm{V}=$ volume of methyl red solution used $(l)$ and $\mathrm{w}=$ weight of biocarbon used $(\mathrm{g})$.

Evaluation of Equilibrium Data: COD reduction experimental data were evaluated with Langmuir and Freundlich isotherm models

Langmuir isotherm model was employed to estimate the maximum reduction capacity and the linear expression is stated in eqn. 5 .

$$
\frac{\mathrm{C}_{\mathrm{e}}}{\mathrm{q}_{\mathrm{e}}}=\frac{\mathrm{K}_{\mathrm{L}}}{\mathrm{q}_{\max }}+\left(\frac{1}{\mathrm{q}_{\max }}\right) \mathrm{C}_{\mathrm{e}} \ldots \ldots \ldots \ldots \ldots \ldots . \ldots
$$

Where $\mathrm{K}_{\mathrm{L}}=$ Langmuir constant $\left(l \mathrm{mg}^{-1}\right)$ and $\mathrm{q}_{\max }=$ maximum $\mathrm{COD}$ reduction $(\mathrm{mg} / \mathrm{g}), \mathrm{C}_{\mathrm{e}}=$ equilibrium COD reduction and $\mathrm{q}_{\mathrm{e}}=$ COD reduction capacity (mg/g).

Plot of $C_{e} / q_{e}$ against $C_{e}$ is expected to give linear graph with slope $=1 / q_{\max }$ and interception $=$ $K_{l} / q_{\max }$

Freundlich isotherm model was used to estimate the degree of COD reduction. The linear form of this equation is given in eqn. 6 .

$$
\log \mathrm{q}_{\mathrm{e}}=\log \mathrm{K}_{\mathrm{F}}+\frac{1}{n} \log C_{e} \ldots \ldots \ldots \ldots \ldots \ldots
$$

To determine the constants $K_{F}$ and $n$, plot of $\log q_{e}$ against $\log C_{e}$ is expected to be linear. The slope $=\frac{1}{n}$ and intercept $=\log \mathrm{K}_{\mathrm{F}}$.

Evaluation of Favorability of COD Reduction: The favourability of COD degradation of methyl red in water was predicted using the separation factor as presented $\left(\mathrm{S}_{\mathrm{F}}\right)$ in eqn. 7.

$$
S_{F}=\frac{1}{1+K_{L} C_{o}} \ldots \ldots \ldots \ldots \ldots . \cdots
$$

Where $\mathrm{S}_{\mathrm{F}}=$ favourability factor, $\mathrm{C}_{\mathrm{o}}=$ initial methyl red concentration and $\mathrm{K}_{\mathrm{L}}=$ Langmuir constant.

Kinetic Model Analysis of COD Reduction

Pseudo-first and - second order kinetic behaviors were examined using COD reduction experimental data obtained from refluxing time-dependent analysis.

Pseudo - First Order Kinetics: The linear pseudo - first order kinetic model shown in eqn. 8 was used

$$
\log \left(\mathrm{q}_{\mathrm{e}}-\mathrm{q}_{\mathrm{t}}\right)=\log \mathrm{q}_{\mathrm{e}}-\left(\mathrm{k}_{1} / 2.303\right) \mathrm{t} \ldots \ldots . .8
$$

Where $\mathrm{q}_{\mathrm{e}}=$ COD reduction capacity $(\mathrm{mg} / \mathrm{g}), \mathrm{q}_{\mathrm{t}}=$ COD reduction capacity of methyl red in water at any time $t$ $(\mathrm{mg} / \mathrm{g}), \mathrm{k}_{1}=$ pseudo-first order rate constant $\left(\mathrm{min}^{-1}\right)$ and $\mathrm{t}=$ time $(\min )$.

Plotting computed values of $\log \left(\mathrm{q}_{\mathrm{e}}-\mathrm{q}_{\mathrm{t}}\right)$ against $\mathrm{t}$ (min) is expected to give a linear graph to enable the computation of slope $\left(\mathrm{q}_{\mathrm{e}}\right)$ and intercept $\left(\mathrm{k}_{1}\right)$.

Pseudo - Second order Kinetics: Ho and co-workers (1995) proposed a linear equation to measure the 
pseudo-second-order kinetic rate which is shown in eqn. 9.

$$
\frac{t}{q_{t}}=\frac{1}{h_{o}}+\frac{1}{q_{e}} \ldots \ldots \ldots \ldots \ldots \ldots
$$

Where $\mathrm{q}_{\mathrm{e}}=$ COD reduction capacity $(\mathrm{mg} / \mathrm{g}), \mathrm{q}_{\mathrm{t}}=\mathrm{COD}$ reduction capacity of methyl red in water at any time $\mathrm{t}$ $(\mathrm{mg} / \mathrm{g}), \mathrm{k}_{2}=$ pseudo-second-order rate constant $(\mathrm{g} / \mathrm{mg}$. $\min ), \mathrm{t}=$ time $(\min ), h_{o}=$ initial COD reduction rates (mg/g. $\mathrm{min})$.

If $\frac{t}{q_{t}}$ is plotted against $\mathrm{t}$, a straight line graph is likely to be obtained, with slope and intercept that may be used to calculate the initial COD reduction rate and the pseudo-second-order rate constants.

Thermodynamic Analysis of COD Reduction: The apparent Gibbs free energy was obtained using eqn. 10.

$$
\Delta \mathrm{G}^{0}=-\mathrm{RT} \ln \mathrm{K}_{\mathrm{L}}
$$

Where $\mathrm{K}_{\mathrm{L}}=$ thermodynamic equilibrium constant of the Langmuir model.

Analytical Precision and Quality Control: Careful quality control measures such as washing of glassware, use of analytical grade reagent, use of freshly preparing working standards, reagents and blanks, and comparing analytical procedures by use of commercial activated carbon (AquaNucha) were appropriately adopted.

Statistical Analysis of Experimental Data: The consistency of COD attenuation data were done making triplicate analysis and computation of mean, standard deviations, standard errors and analysis of variance (ANOVA).

\section{RESULTS AND DISCUSSION}

Biocarbon production from the biomass was achieved by pyrolysis in an inert atmosphere and the resultant series of chemical reactions are illustrated as.

$$
\begin{gathered}
\underbrace{10\left(\mathrm{C}_{6} \mathrm{H}_{10} \mathrm{O}\right.}_{\text {lignocellulose }})(\mathrm{s}) \stackrel{\Delta}{\rightarrow} \underbrace{\mathrm{C}_{6} \mathrm{H}_{8} \mathrm{O}}_{\text {Biocarbon }}(\mathrm{s})+\mathrm{H}_{2} \mathrm{O}(\mathrm{l})+\mathrm{CO}_{2}(\mathrm{~g})+\mathrm{CO}(\mathrm{g})+\underbrace{\mathrm{C}_{6} \mathrm{H}_{10} \mathrm{O}_{5}}_{\text {Levoglucosan (tar) }}(s) \\
3 \mathrm{C}_{6} \mathrm{H}_{10} \mathrm{O}_{5}(\mathrm{~s}) \stackrel{\Delta}{\rightarrow} 8 \mathrm{H}_{2} \mathrm{O}(\mathrm{g})+\mathrm{C}_{6} \mathrm{H}_{8} \mathrm{O}(\mathrm{s})+2 \mathrm{CO}(\mathrm{g})+2 \mathrm{CO}_{2(\mathrm{~g})}+\mathrm{CH}_{4}(\mathrm{~g})+\mathrm{H}_{2}(\mathrm{~g})+7 \mathrm{C}(\mathrm{s}) \\
2 \mathrm{C}_{6} \mathrm{H}_{8} \mathrm{O}(\mathrm{s})+6 \mathrm{H}_{2} \mathrm{O}(\mathrm{l}) \rightarrow 14 \mathrm{H}_{2}(\mathrm{~g})+3 \mathrm{CO}_{2}(\mathrm{~g})+2 \mathrm{CO}(\mathrm{g})+7 \mathrm{C}(\mathrm{s})
\end{gathered}
$$

Impregnation of the biocarbon with $\mathrm{H}_{3} \mathrm{PO}_{4}$ and $\mathrm{KOH}$ produced modified biocarbons in a series of reactions (Ali et al., 2014).

$$
\begin{gathered}
\mathrm{H}_{3} \mathrm{PO}_{4}(\mathrm{l})+\mathrm{HO}-\text { cellulose }(\mathrm{s}) \rightarrow \text { Cellulose }-\mathrm{O}-\mathrm{PO}_{3} \mathrm{H}_{2}(\mathrm{~s})+\mathrm{H}_{2} \mathrm{O}(\mathrm{l}) \\
\text { Cellulose }-\mathrm{O}-\mathrm{PO}_{3} \mathrm{H}_{2}(\mathrm{~s}) \stackrel{\Delta}{\rightarrow} \mathrm{PO}-\mathrm{C}(\mathrm{s})+\mathrm{H}_{2} \mathrm{O}(\mathrm{l})+\mathrm{H}_{2}(\mathrm{~g})+\mathrm{CO}_{2}(\mathrm{~g})+\mathrm{CO}(\mathrm{g})+\mathrm{CH}_{4}(\mathrm{~g}) \\
\mathrm{PO}-\mathrm{C}(\mathrm{s}) \rightarrow \mathrm{C}(\mathrm{s})+\mathrm{H}_{3} \mathrm{PO}_{4}(\mathrm{l}) \\
\mathrm{C}_{\mathrm{n}} \mathrm{H}_{x} \mathrm{O}_{\mathrm{y}}(\mathrm{s})+\mathrm{KOH}(\mathrm{l}) \stackrel{\Delta}{\rightarrow}(\text { Cellulose }-\mathrm{O}-\mathrm{K})(\mathrm{s})+\mathrm{H}_{2} \mathrm{O}(\mathrm{l}) \\
(\text { Cellulose }-\mathrm{O}-\mathrm{K})(\mathrm{l}) \stackrel{\Delta}{\rightarrow} \mathrm{C}(\mathrm{s})+\mathrm{C}+\mathrm{C}-\mathrm{O}-\mathrm{K}(\mathrm{s})+\operatorname{tar}(\mathrm{s})+\operatorname{Gases}(\mathrm{g})
\end{gathered}
$$

Physicochemical Characteristics: In order to access the appropriateness of the biocarbons obtained from Nipa palm leaves as adsorbent and to compare with commercial activated carbon (CAC), eight physicochemical properties were evaluated (Table 1). The carbon yield obtained for biocarbons were $33.7 \pm$ $0.96 \%$ (PMB), $56 \pm 0.19 \%$ (AMB) and $67.6 \pm 0.21 \%$ (BMB) which were compared with CAC $(98.53 \pm 1.8)$. The results show that, the highest carbon yield (67.6 \pm $0.21 \%$ ) was recorded for base reagent activated biocarbon (BMB). CAC data was compared with Nipa derived biocarbons and it revealed that $\mathrm{BMB}$ is of higher quality than AMB and PMB.

The relative loss of carbon during transportation, handling, and regeneration is related to mechanical strength, which can be measured by attrition level. The percent attrition obtained for the biocarbons and CAC are $64.26 \pm 1.11,42.11 \pm 0.99,82.2 \pm 1.03$ and $94.1 \pm$ 1.09 for $\mathrm{PMB}, \mathrm{AMB}, \mathrm{BMB}$ and $\mathrm{CAC}$ respectively. The attrition of commercial granulated activated carbon (GAC) is in range of 70-90 \% (Adowei et al., 2015). 
From the data, the attrition levels of biocarbons

than

PMB and

AMB

respectively produced from Nipa palm shows that BMB is harder

Table 1: Physicochemical physiognomies of biocarbons and CAC

\begin{tabular}{lllll}
\hline & \multicolumn{4}{c}{ Biocarbons } \\
\hline & PMB & AMB & BMB & CAC \\
Carbon Yield (\%) & $33.7 \pm 0.96$ & $56 \pm 0.19$ & $67.6 \pm 0.21$ & $98.53 \pm 1.8$ \\
Attrition (\%) & $64.26 \pm 1.11$ & $42.11 \pm 0.99$ & $82.2 \pm 1.03$ & $94.1 \pm 1.09$ \\
pH & $7.32 \pm 0.44$ & $6.41 \pm 0.42$ & $7.81 \pm 0.47$ & $7.21 \pm 0.38$ \\
Ash content (\%) & $12.5 \pm 1.09$ & $10.2 \pm 1.08$ & $7.4 \pm 1.05$ & $17.2 \pm 1.06$ \\
Moisture content (\%) & $12 \pm 0.06$ & $10 \pm 0.03$ & $11 \pm 0.02$ & $14 \pm 0.08$ \\
Iodine number (mg/g) & $334 \pm 2.17$ & $298 \pm 1.96$ & $224 \pm 2.06$ & $254 \pm 2.11$ \\
Porosity (\%) & $75 \pm 1.33$ & $79 \pm 1.21$ & $65 \pm 0.98$ & $70 \pm 1.22$ \\
Surface area $\mathbf{~ m}^{2} / \mathbf{g}$ & $546 \pm 0.45$ & $488 \pm 0.98$ & $471 \pm 1.02$ & $522 \pm 0.79$ \\
\hline
\end{tabular}

The acidity or basicity of activated carbon is dependent on several factors such as preparation, surface active oxygen groups and treatment method. The biocarbon derived from acidic reagent treatment was slightly lower in $\mathrm{pH}$ than those impregnated with $\mathrm{KOH}$ and $\mathrm{H}_{2} \mathrm{O}$. The acidity or basicity measured in terms of $\mathrm{pH}$ shows levels of $6.41 \pm 0.11$ to $7.81 \pm 0.12$ which is within the acceptable $\mathrm{pH}$ range $(6-8)$ for activated carbons in most applications (Qureshi et al., (2008). Relatively low biocarbon ash content is desirable because it is a sign of excellent mechanical strength. Biocarbons from Nipa palm leaves generated low percent ash which makes them comparable to CAC. The ash content for the Nipa palm biocarbons were 5.8 $\%$ (PMB), $4.3 \%$ (AMB) and 3.7\% (BMB) respectively.

The removal of volatile constituents in samples during thermo-degradation process can be measured by moisture content. Relatively low moisture content was observed for the biocarbons: PMB (6.5\%), AMB (6.4 $\%)$ and BMB (7.1\%) respectively. According to Aziza and co-workers (2008), the moisture content of CAC ranged between $2-5 \%$. Comparing $\mathrm{CAC}$ with Nipa palm biocarbons show that, PMB, AMB and BMB may serve as potential resources for adsorption process in a fixed bed column reactors. Development of internal porosity happens in thermo-degradation of carbon to create active surfaces. Measurement of the biocarbons porosity revealed that BMB had the highest porosity of $79 \%$, followed by PMB (73\%) and AMB (66\%).

Surface area of biocarbon is an important parameter to access the potential adsorption suitability of a precursor material. Specific surface area of the biocarbons are 488, 441 and $681 \mathrm{~m}^{2} / \mathrm{g}$ for PMB, AMB and BMB respectively. The data showed that BMB had the largest surface area, which is an essential criteria for improved adsorbent capacity and efficiency because surface area provides enormous pore volumes thereby increasing the number of available active sites. The quantity of iodine adsorbed by one gram of biocarbon at equilibrium is a measure of the iodine number and the values for the biocarbons produced from Nipa palm leaves follow the order: BMB $(814.5 \mathrm{mg} / \mathrm{g})>$ PMB $(622.8 \mathrm{mg} / \mathrm{g})>$ AMB $(431 \mathrm{mg} / \mathrm{g})$. Higher iodine number indicates greater porosity, consequently, the data shows that BMB is a better adsorbent material with superior micropore content than the others.

Optimization of COD Reduction of Methyl Red in Water Optimum process conditions such as biocarbon dosage, initial methyl red concentration, initial $\mathrm{pH}$ of methyl red solution, and refluxing time for digestion of methyl red were evaluated to assess their effects during COD reduction of methyl red in water by Nipa palm biocarbons and commercial activated carbons.

\section{Effect of Biocarbon Dosage on COD Reduction}

The measured quantity of an adsorbent used to contact aqueous solution has significant effect on the process of removal. Several investigations (Kapadia et al., 2000, Tarawou et al., 2007) have revealed that, large dosage of biocarbon provides greater sorption sites, porosity and surface area thereby enhancing the attenuation capacity. The optimum dosage of biocarbons and CAC were evaluated by percent COD removal of methyl red in water (Figure 2). The result showed that, percent COD reduction by $\mathrm{PMB}, \mathrm{AMB}, \mathrm{BMB}$ and $\mathrm{CAC}$ increased with increase in biocarbon dosage with maximum dosage obtained around $0.8 \mathrm{~g} / 50 \mathrm{ml}$, which translates to $93.1 \%$ (PMB), 93.7\% (AMB), 95.1\% $(\mathrm{BMB})$ and $96.6 \%(\mathrm{CAC})$ respectively at $30^{\circ} \mathrm{C}$. Comparative analysis of COD reduction between Nipa biocarbons and $\mathrm{CAC}$ showed that, $\mathrm{BMB}$ gave optimum $\mathrm{COD}$ reduction for methyl red in water. 


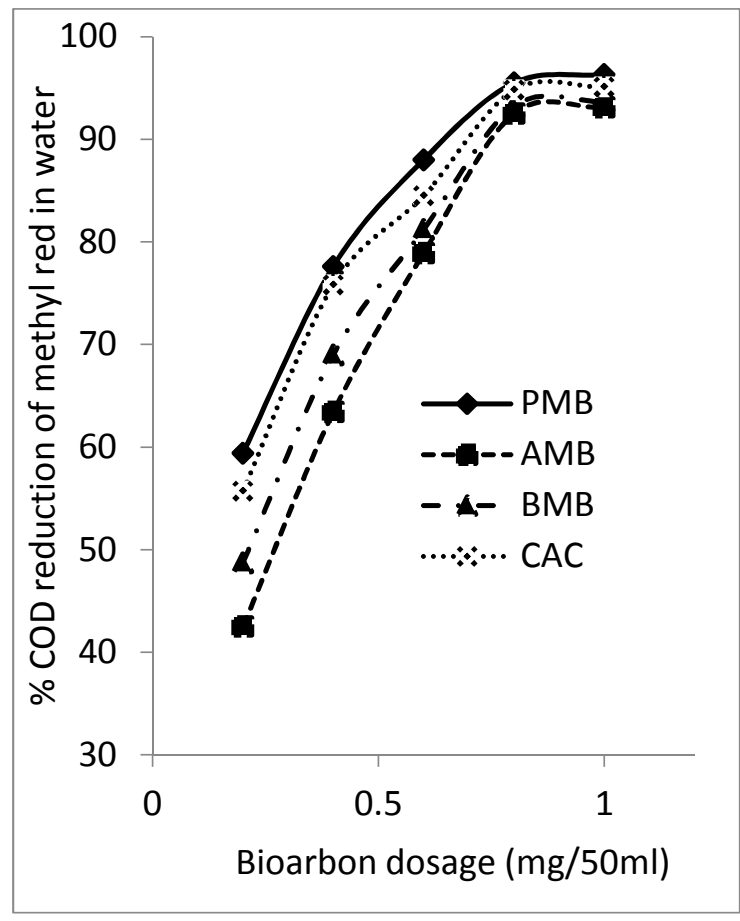

Fig 2: Effect of biocarbon dosage on COD reduction of methyl red in water

Effect of Initial Methyl Red Concentration on COD Reduction: The relationship between percent COD reduction and initial methyl red concentrations for the biocarbons and commercial activated carbon are presented in Figure 3. Optimal COD reduction for methyl red in water by $\mathrm{PMB}, \mathrm{AMB}, \mathrm{BMB}$ and $\mathrm{CAC}$ were $82.7 \%, 76.7 \%, 83.5 \%$, and $83.3 \%$ respectively. The data showed that percent COD reduction increased from lower concentration of $20 \mathrm{mg} / \mathrm{l}$ to a maximum around $40 \mathrm{mg} / \mathrm{l}$ and gradually decreased for the remaining monitoring concentrations. At lower concentrations, significant amount of methyl red was attenuated from solution since the medium could interact with the binding sites on the surface of the biocarbons to yield higher percent reduction. At higher concentrations of methyl red in water, lower attenuation were observed because surface saturation on the biocarbons occur quickly and there were no further take up of methyl red, hence, the amount reduced become smaller as initial concentration increased

Effect of $p H$ on COD Reduction: Methyl red is an anionic azo dye (Ashraf et al., 2006), which turns red to yellow within $\mathrm{pH}$ range of 4.4 to $6.2 \mathrm{pH}$ of dye solutions play significant role in tinting of textile and paper materials. During dyeing process, anions are favorably attached to materials at lower $\mathrm{pH}$ values due to availability of $\mathrm{H}^{+}$ions, while at high $\mathrm{pH}$ values, cations are attracted to the materials because of the presence of negatively charged surface sites on materials. The effect of $\mathrm{pH}$ can be explained by surface charges on the attracting material. Hence, the reduction of methyl red in water as a function of $\mathrm{pH}$ was also investigated.

The percent COD reduction of methyl red by the biocarbons and CAC as presented in Figure 4 showed that $\mathrm{COD}$ reduction strength rises as $\mathrm{pH}$ value increased from 2 to 9 reaching optimal value at $\mathrm{pH}$ 5. It was observed that, poor COD reduction of methyl red occurred at the two extremes of the $\mathrm{pH}$ levels. Excellent methyl red degradation was achieved at $\mathrm{pH}$ range $4-6$.

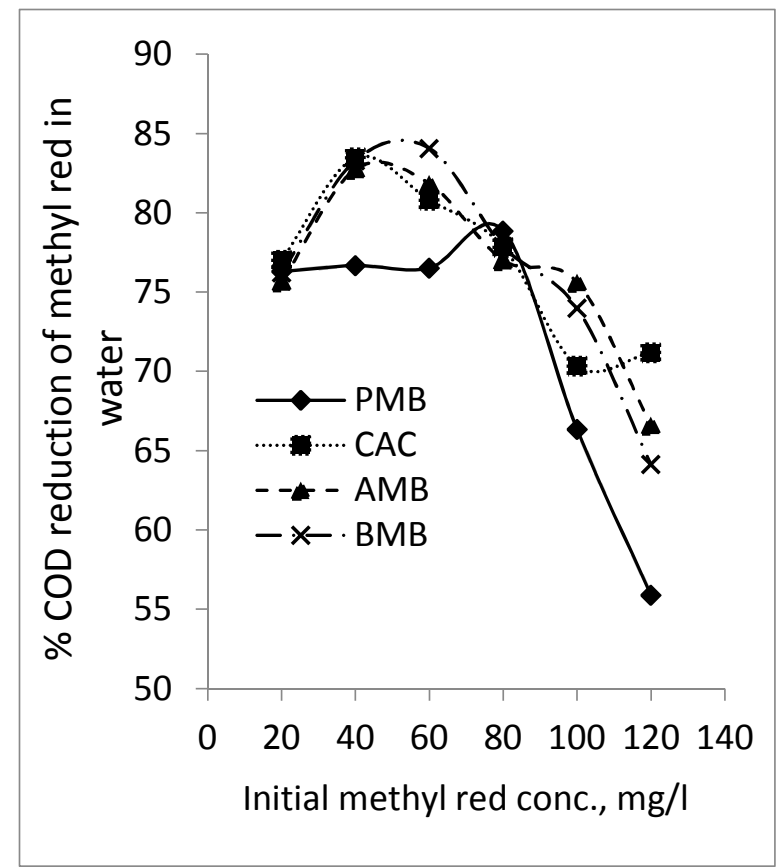

Fig 3: Effect of initial methyl red concentration on COD attenuation 


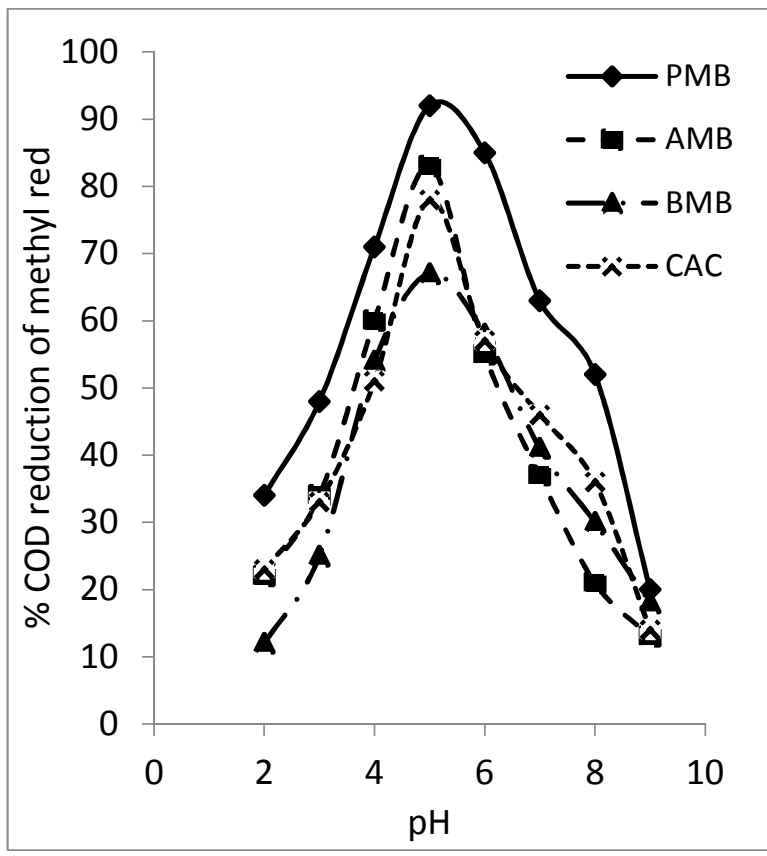

Fig 4: Effect of $\mathrm{pH}$ on COD reduction of methyl red in water

Effect of Refluxing Time on COD Reduction: The refluxing time is essential in the consideration of the optimum COD reduction of organic contaminant and may be adopted in providing optimum degradation time. The consequence of refluxing time on COD reduction at fixed methyl red initial concentration (100 $\mathrm{mg} / \mathrm{l})$ and fixed refluxing temperature $\left(150^{\circ} \mathrm{C}\right)$ by the biocarbons and CAC are shown in Figure 5. The data indicates that degradation time is not dependent on biocarbon type; and maximum COD reduction could be achieved within $30 \mathrm{~min}$ of refluxing. The equilibrium time indicate the completeness of degradation of organic components. The rapid degradation time indicates that easy-to-digest samples may be studied with confidence in short period of time.

Equilibrium Models Treatment of Experimental Data Equilibrium models are essential conditions in the design of adsorption systems because they provide baseline data for possible scale-up operation. Equilibrium COD reduction of methyl red in water by biocarbons and CAC were estimated by Langmuir and Freundlich equilibrium models

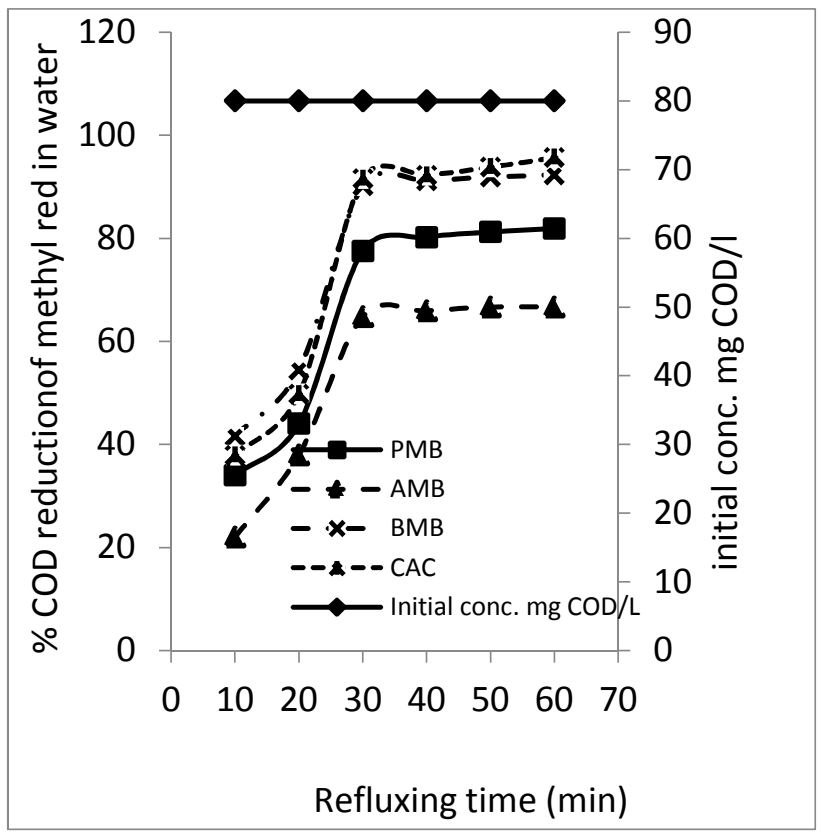

Fig 5: Effect of refluxing time on COD reduction of methyl red in water

Langmuir Isotherm: Langmuir isotherm has a hypothetical basis and assumed that a surface contains a specified quantity of equal sites where certain class of molecules can stick physically or chemically. In order to ease the approximation of the COD reduction capacity, the experimental data of methyl red in by biocarbon and CAC were applied to the Langmuir isotherm equation by plotting $\left(\frac{C_{e}}{q_{e}}\right)$ against $\mathrm{C}_{\mathrm{e}}$ (Figure 6). The computed COD reduction capacities $\left(\mathrm{q}_{\max }\right.$, $\mathrm{mg} / \mathrm{g})$, Langmuir constants $\left(\mathrm{K}_{\mathrm{L}}, \mathrm{dm}^{3} / \mathrm{g}\right)$, and coefficient of determinations $\left(\mathrm{R}^{2}\right)$ for methyl red removal in water are presented Table 2 . The maximum COD reduction $\left(\mathrm{q}_{\max }\right)$ capacities obtained were $2.15 \mathrm{mg} / \mathrm{g}$ (PMB), 8.73 $\mathrm{mg} / \mathrm{g}$ (AMB), $11.83 \mathrm{mg} / \mathrm{g}$ (BMB) and $62.60 \mathrm{mg} / \mathrm{g}$ for CAC respectively. Amongst the Nipa palm biocarbons, the Langmuir maximum COD reduction COD reduction capacity of BMB for methyl red is higher than PMB and AMB but relatively lower CAC. The Langmuir coefficient for PMB $\left(8.70 \times 10^{-1} \mathrm{dm}^{3} / \mathrm{g}\right)$ to attenuate methyl red in water was greater than that of AMB and $\mathrm{BMB}$, indicative of requiring higher energy for action. Comparing the Langmuir constant coefficients values for Nipa palm biocarbons and CAC demonstrations that $\mathrm{BMB}$ is a better biocarbon option than PMB and AMB 


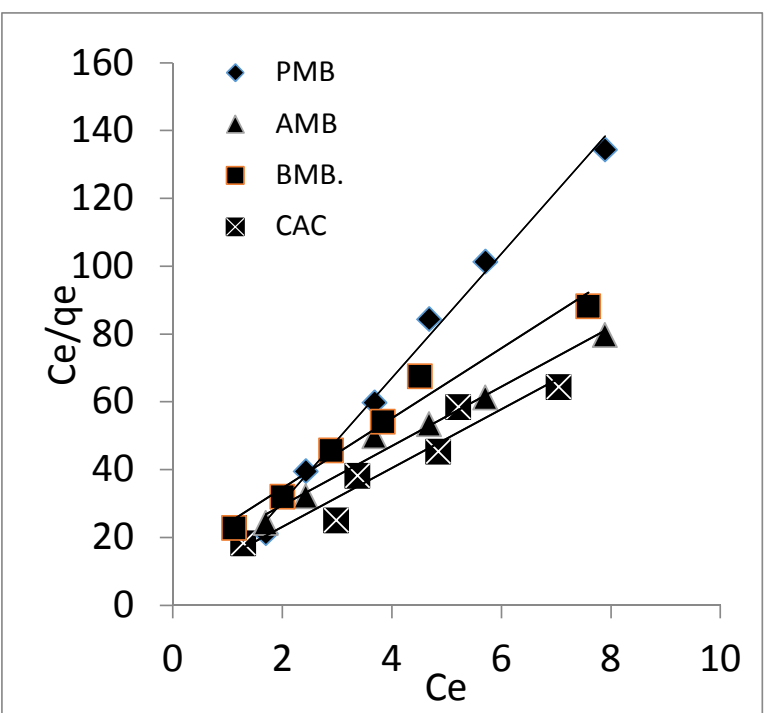

Fig 6: Langmuir equilibrium isotherm model of COD reduction of methyl red in water
Freundlich isotherm model provides experimental equation for testing non-perfect materials that have heterogeneous surfaces for attraction. The model is adopted to approximate data for physical adsorption systems especially in liquids and was used to approximate COD reduction strength (figure 7) of methyl red in water by $\mathrm{PMB}, \mathrm{AMB}, \mathrm{BMB}$ and $\mathrm{CAC}$. The Freundlich constant, $\mathrm{K}_{\mathrm{F}}$, an equilibrium partition coefficient associated with bonding energy provided the degree of COD reduction. In practice, large $\mathrm{K}_{\mathrm{F}}$ value is a pointer to enhanced contaminant reduction. The $\mathrm{K}_{\mathrm{F}}$ values obtained for COD reduction of methyl red in water by different biocarbons and $\mathrm{CAC}$ were 0.207 (PMB), 0.570 (AMB), 0.447 (BMB) and 0.783 (CAC) respectively.

\section{Freundlich Isotherm}

Table 2 Langmuir maximum COD reduction $\left(\mathrm{q}_{\max }\right)$ capacity $(\mathrm{mg} / \mathrm{g})$ for methyl red in water

\begin{tabular}{lllllll}
\hline & \multicolumn{2}{c}{ Langmuir isotherm Parameters } & \multicolumn{4}{c}{ Freundlich Isotherm Parameters } \\
\hline & $\mathrm{q}_{\max }(m g / g)$ & $\left(\mathrm{K}_{\mathrm{L}}, \mathrm{dm}^{3} / \mathrm{g}\right)$ & $\mathrm{R}^{2}$ & $\mathrm{~K}_{\mathrm{F}}$ & $\mathrm{n}$ & $\mathrm{R}^{2}$ \\
PMB & 2.15 & $8.70 \times 10^{-1}$ & 0.945 & 0.207 & 0.357 & 0.899 \\
AMB & 8.73 & $9.49 \times 10^{-1}$ & 0.875 & 0.570 & 0.1605 & 0.898 \\
BMB & 11.83 & $7.0 \times 10^{-1}$ & 0.981 & 0.447 & 0.6209 & 0.906 \\
CAC & 62.60 & $2.0 \times 10^{-1}$ & 0.994 & 0.783 & 0.8765 & 0.927 \\
\hline
\end{tabular}

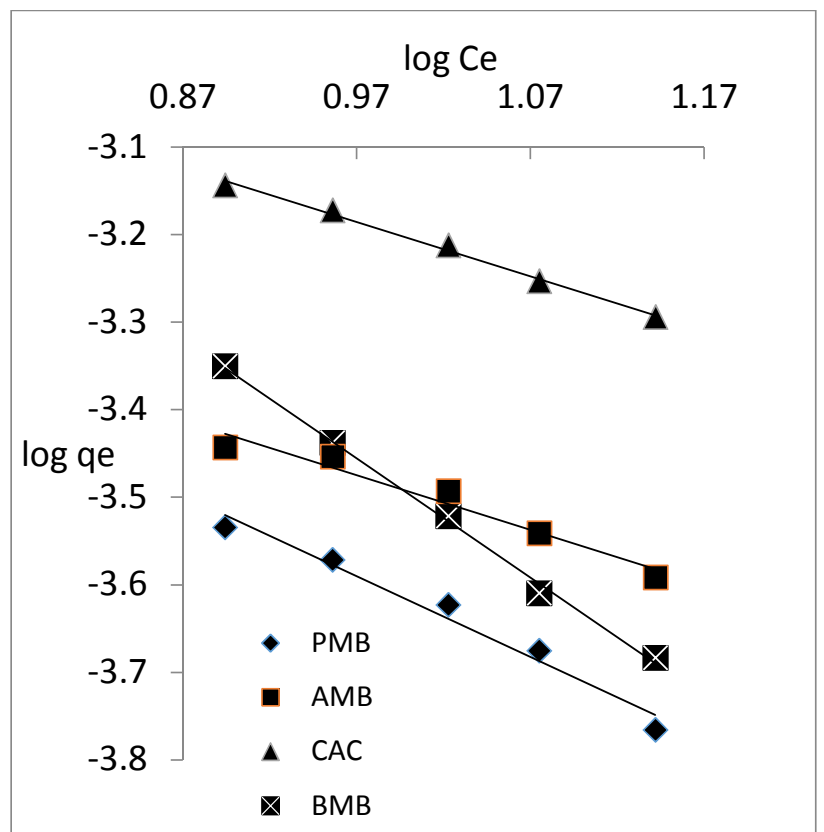

Fig 7: Freundlich equilibrium isotherm model of COD reduction of methyl red in water 
COD Attenuation Favourability: The favourability or unfavourability of reducing COD in water contaminated by methyl red was assessed using the Langmuir isotherm coefficient $\left(\mathrm{K}_{\mathrm{L}}\right)$ and Freundlich isotherm model parameter $(1 / \mathrm{n})$. To predict the favourable or unfavourable by $\mathrm{K}_{\mathrm{L}}$, the dimensionless separation index $\left(\mathrm{S}_{i}\right)$ proposed by Poots and co-workers (1978) was applied. In its application, reduction favourability or unfavourability may be assessed based on the value of $\mathrm{S}_{i}$ obtained from computation. In so doing, if computed value of $\mathrm{S}_{i}>1$, COD reduction is unfavourable and if 0 $<\mathrm{S}_{i}<1$, COD reduction is favourable. In the case of Freundlich 1/n parameter; a favourable COD reduction corresponds to a value of $0<1 / \mathrm{n}<1$ while unfavourability tallies with $1 / \mathrm{n}>1$. Computational data reveal values of $S_{i}<1$ and $1 / \mathrm{n}<1$, therefore COD reduction of methyl red in water using Nipa biocarbon is favourable and the technique may be adopted as a practicable option for removing low molecular weight organic contaminants in aqueous system.

Kinetic Model Treatment of Experimental Data: In water and wastewater treatment systems, kinetic models can be used to predict the rate of reactions for designing appropriate treatment plants, such studies may provide insight into the reaction pathways and mechanisms. Kinetic models extensively used in this regards are Langergren pseudo-first order kinetic model (Gupta et al., 1994; Gaid et al 1994, Horsfall et al., 2005) and pseudo-second order kinetic model (Ho et al., 1995, 1998 and Horsfall and Spiff, 2005. In this paper, these two models were adopted to judge the reflux time experimental data from COD reduction of methyl red in water, whose parameters are presented in Table 3.

Table 3: COD reduction parameters from pseudo-first and - second order rate models

\begin{tabular}{|c|c|c|c|c|c|c|c|c|}
\hline \multirow[t]{2}{*}{ Carbons } & \multicolumn{4}{|c|}{ Pseudo-first order equation parameters } & \multicolumn{4}{|c|}{$\begin{array}{l}\text { Pseudo-second order equation } \\
\text { parameters }\end{array}$} \\
\hline & PMB & $\mathrm{AMB}$ & $\mathrm{BMB}$ & CAC & PMB & AMB & $\mathrm{BMB}$ & $\overline{\mathrm{CAC}}$ \\
\hline $\mathrm{q}_{\mathrm{e}}, \mathrm{mg} / \mathrm{g}$ & 5.32 & 2.10 & 6.10 & 7.90 & 6.41 & 2.80 & 8.77 & 9.48 \\
\hline $\mathrm{r}^{2}$ & 0.85 & 0.416 & 0.822 & 0.854 & 0.997 & 0.995 & 0.999 & 0.997 \\
\hline $\mathrm{k}_{1}$ and $\mathrm{k}_{2} \times 10^{-3}$ & 4.38 & 1.15 & 9.66 & 4.38 & 9.19 & 6.0 & 3.02 & 2.24 \\
\hline $\mathrm{h}_{\mathrm{o}}$ & & & & & 0.357 & 0.411 & 0.641 & 0.809 \\
\hline
\end{tabular}

$\mathrm{q}_{\mathrm{e}}=$ COD reduction capacity at equilibrium, $\left(\mathrm{mg} \mathrm{g}^{-1}\right)$,

$\mathrm{r}^{2}=$ Coefficient of determinations

$\mathrm{k}_{1}=$ Pseudo-first order rate constant, $\left(\mathrm{min}^{-1}\right)$

$\mathrm{k}_{2}=$ Pseudo-second order rate constant, $\left(\mathrm{mg} \mathrm{g}^{-1} \mathrm{~min}^{-1}\right)$

$\mathrm{h}_{\mathrm{o}}=$ Ho's constant related to initial COD reduction rate, $\left(\mathrm{mg} \mathrm{g}^{-1} \mathrm{~min}^{-1}\right)$

\section{Langergren Pseudo - First Order Kinetics}

Langergren (1998) pseudo-first order kinetic model was used to evaluate the rate constants (Fig 8). The data showed that the rate constants $\left(\mathrm{k}_{1}, \mathrm{~min}^{-1}\right)$ for COD reduction of methyl red in water are $4.38 \times 10^{-3}, 1.15 \mathrm{x}$ $10^{-3}, 9.66 \times 10^{-3}$ and $4.38 \times 10^{-3}$ for PMB, AMB, BMB and $\mathrm{CAC}$ respectively. The pseudo-first order rate constants, $\mathrm{k}_{1}$, for $\mathrm{BMB}$ was higher than $\mathrm{PMB}$ and AMB. The values for coefficient of determinations, $R^{2}$, from the Langergren pseudo-first order kinetic plot are $0.854,0.416,0.8220 .854$ for PMB, AMB, BMB and CAC. The plots are non-linear, indicating that pseudofirst order kinetic is unsuitable to describe the COD reduction process of methyl red in water by the biocarbons and CAC.

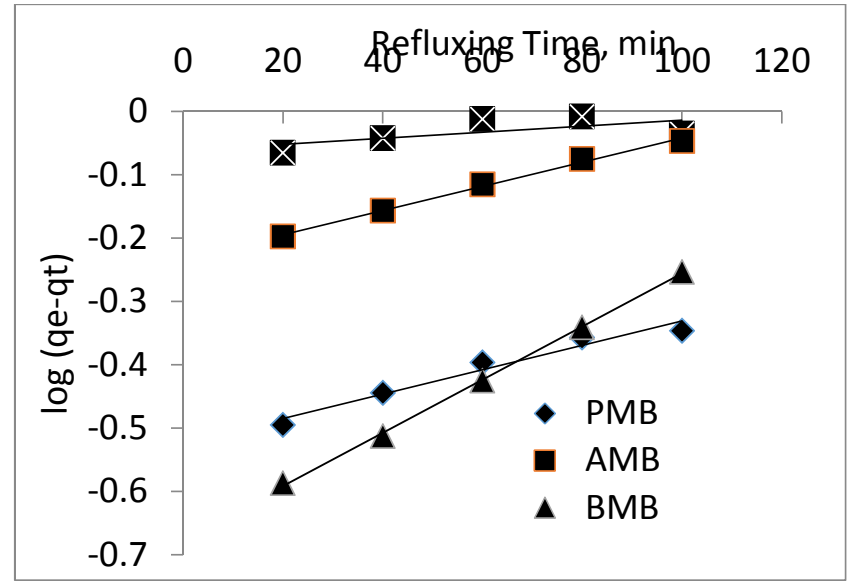

Fig 8. Lagergren COD reduction plots for methyl red in water 
Pseudo - Second order Kinetics: Since the expected curvature did not fit the experimentally derived data for the pseudo-first order kinetic model; a pseudo-second order rate equation (Ho et al., 1995) was applied by plots of $\frac{t}{q_{t}}$ against $t$ (Figure 9). The equilibrium COD reduction capacities $(\mathrm{mg} / \mathrm{g})$ obtained from the graph for biocarbons and $\mathrm{CAC}$ were 13.94 (PMB), 2.80 (AMB), 51.77 (BMB) and 53.48 (CAC); respectively. The behaviour indicates that PMB has the lowest COD reduction capacity. The rate constants $\left(\mathrm{k}_{2}, \mathrm{~g} / \mathrm{mg}\right.$.min $)$ were $9.19 \times 10^{-3}$ (PMB), $26.0 \times 10^{-3}$ (AMB), $0.302 \times 10^{-}$ ${ }^{3}$ (BMB) and $0.224 \times 10^{-3}$ (CAC) respectively. The $\mathrm{R}^{2}$ values for $\mathrm{COD}$ reduction by the biocarbons and $\mathrm{CAC}$ are $>>0.995$, indicating that the pseudo-second order rate law is very good in describing the COD reduction behaviour of the biocarbons.

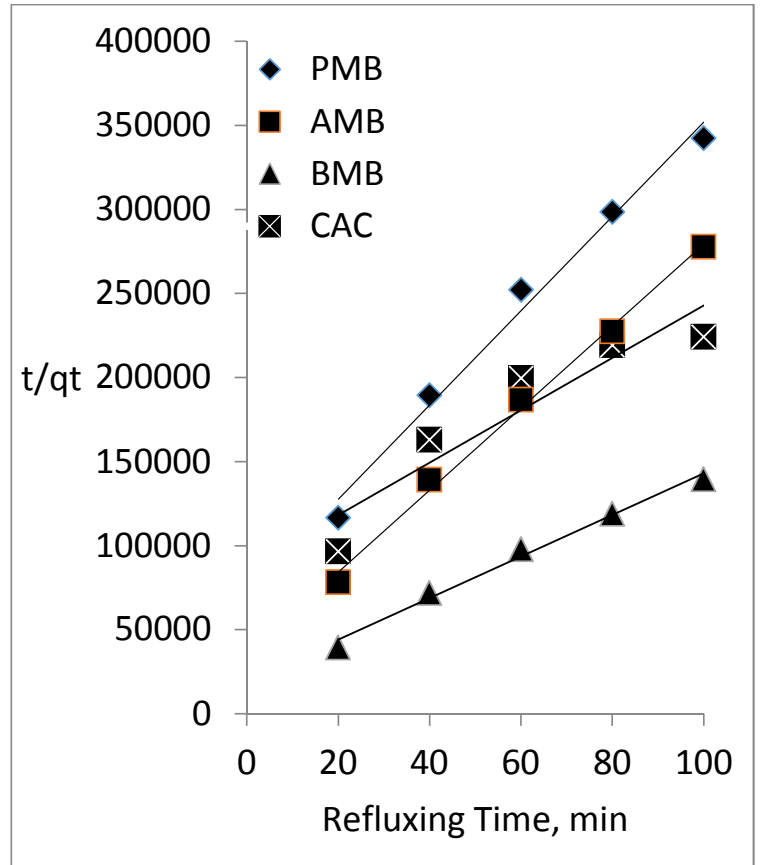

Fig 9: Pseudo-second order COD reduction plots for methyl red in water

Thermodynamic Model Treatment of Experimental Data
Spontaneity of COD reduction process of methyl red in water was assessed by computing the apparent Gibbs free energy $\left(\Delta G^{o}\right)$ using Langmuir isotherm model equilibrium constant $\left(\mathrm{K}_{\mathrm{L}}\right)$. By this assessment, a process is spontaneous at a given temperature, if $\Delta G^{o}$ is a negative quantity with values up to $-20 \mathrm{~kJ} / \mathrm{mol}$ and non-spontaneous if $\Delta G^{o}$ is a positive quantity. The apparent Gibbs free energy of COD reduction for methyl red in water by biocarbons and CAC as computed are presented in Table 4. The values of $\Delta G^{o}$ $(\mathrm{kJ} / \mathrm{mol})$ computed for PMB, AMB, BMB and CAC are $-3.51,-0.13,-5.90$ and -4.06 respectively. The negative values of $\Delta G^{o}$ indicate that COD reduction of methyl red in water using biocarbons and CAC are spontaneous in nature requiring negligible amount of energy. Since the values of $\Delta G^{o}$ obtained were $<-20$ $\mathrm{kJ} / \mathrm{mol}$, it means that the interactions between methyl red and biocarbons are electrostatic and the prime mechanism is physisorption.

Table 4: Computation of $\Delta G^{o},(\mathrm{~kJ} / \mathrm{mol})$ of COD attenuation of methyl red in water

\begin{tabular}{|l|l|l|l|l|}
\hline Carbons & PMB & AMB & BMB & CAC \\
\cline { 2 - 5 } & -3.51 & -1.31 & -5.90 & -4.06 \\
\hline
\end{tabular}

Statistical Evaluation of COD Reduction Capacity Studies: The reliability of the analytical data were assessed by one-way ANOVA in order to measure the uncertainties associated with computed results. In so doing a null hypothesis to compare the COD reduction potential of biocarbons ( $P M B, A M B$ and $B M B$ ) to reduce methyl red in water at 0.05 significant level was made. The result shows that, $F_{\text {exp }}(0.74)<F_{\text {crit }}(4.07)$ implying that there is no difference in the potential capacities of the biocarbons to attenuate methyl red in water at the 0.05 significant level. The $p$-value obtained from computation (Table 5 ) is compared with the significance level $(0.05)$. Because the $p$-value (0.5582) > significant level (0.05), there is no significant differences in COD reduction capacity among the biocarbons obtained from Nipa palm leaves.

Table 5 One-Way Analysis of Variance (ANOVA) at $\alpha=0.05$ to compare the Nipa palm biocarbons and CAC

\begin{tabular}{lllllll} 
Sources of Variation & $S S$ & $d f$ & $M S$ & $F$ & $P$-value & F crit \\
\hline Carbons & 55.3681 & 3 & 18.456 & 0.73837 & 0.55817 & 4.06618 \\
Within Groups & 199.964 & 8 & 24.9955 & & & \\
Total & 255.332 & 11 & & & & \\
\hline
\end{tabular}

$S S=$ sums of square $; f=$ degrees of freedom; $M S=$ means of square $; P$-value $=$ Probability value; $F=$ calculated $F$ ratio value; $F$-crit $=$ critical $F$-ratio value 
Conclusions: In conclusion, the series of COD reduction experiments and evaluation of the data by various equilibrium and kinetic models revealed that Nipa palm biocarbons are capable of reducing organic contaminants in aqueous media especially at dilute concentrations. Successive government has developed various programmes in the Niger Delta region to exterminate the Nipa palm plant due to its invading capacity; however, this investigation has revealed that apart from tapping natural resources such as sugar, alcohol, paper and food stuff from the Nipa palm, its waste could be useful as an industrial source for production of biocarbons for various uses.

Acknowledgement: The authors wish to acknowledge the kind support through a Grant with No W5574-1 provided to P. Adowei by the International Foundation for Science (IFS), Sweden in collaboration with the Organization for the Prohibition of Chemical Weapons (OPCW), Hague.

\section{REFERENCES}

Abechi, S. E, Gimba, C E, Uzairu, A, Dallatu, Y A (2013). Preparation and Characterization of activated carbon from Palm Kernel Shell by Chemical Activation. Research Journal of Chemical Sciences. 3 (7) 54 -61

Abia, A.A.; Horsfall, M. Jr. and Didi, O. (2003). The use of chemically modified and unmodified cassava waste for the removal of $\mathrm{Cd}, \mathrm{Cu}$ and $\mathrm{Zn}$ ions from aqueous solution. Bioresource Technology, 90, (3) 345-348

Adinata D, Wan Daud WMA, Aroua MK. (2007) Preparation and characterization of activated carbon from palm shell by chemical activation with $\mathrm{K}_{2} \mathrm{CO}_{3}$. Bioresource Technology 98: 145-49.

Adowei, P, M. Horsfall Jnr and A. I. Spiff (2012). Adsorption of Methyl Red from Aqueous Solution by Activated Carbon produced from Cassava (Manihot esculenta Cranz) Peel Waste. Innovations in Science and Engineering .2 (2) 2433.

Adowei, P. Spiff, A. I. and Abia, A. A. (2014). Evaluation of Carbonized and Surface-Modified Carbon Produced from Nipa Palm (Nypa Fruiticans Wurmb) Leaves for the Removal of 2(N,N-Dimethyl-4-aminophenyl)-azo-benzene carboxylic acid (DMABA) in Aqueous Solution Acta Chim. Pharm. Indica: 4(3), 2014, 146-156
Ahmad, A.A and Hameed B.H (2009). Reduction of COD and color of dyeing effluent from a cotton textile mill by adsorption onto bamboo-based activated carbon. Journal of Hazardous Materials. 172, (2-3) 1538-1543

Ahmad AL, Loh MM, Aziz JA. 2010. Preparation and characterization of activated carbon from oil palm wood and its evaluation on Methylene blue adsorption. Dyes and Pigments 75: 263-72.

Ahmedna M, Marshal W, Rao M. (2000). Production of Granular activated carbon from selected Agric by products. Bioresource and Technology; 71(2): 113 -123 .

Ali, M. and Ajmal, M N. Deo, 2014. Effect of pH on adsorption process of chromium (VI) with a new low cost adsorbent. Indian J. Environ. Prot., 12: 202-209.

Allen, S. J., Mckay, G., and Porter, J. F. (2004). Adsorption isotherm models for basic dye adsorption by peat in single and binary component systems. Journal of Colloid and Interface Science, 280 , 322-333. http://dx.doi.org/10.1016/j.jcis.2004.08.078

Ash B, Satapathy D, Mukherjee PS, Nanda B, Gumaste JL, Mishra BK, (2006). Characterization and application of activated carbon prepared from coir pith, J.Sci.Ind.Res. 65 1008-1012.

Ashraf, S. S, Muhammad A. R, and Seham A. (2006). Degradation of Methyl Red using Fenton's reagent and the effect of various salts. Dyes and Pigments 69, 74-78,

Aziza A, Odiakosa A, Nwajei G, Orodu V. (2008). Modification and characterization of activated carbon derived from Bumper sawdust and disk sawdust to remove lead (II) and cadmium (II) effluent water. CSN Conference proceeding. Chemical Society of Nigeria. Deltachem; 235-243.

Birhanli, A., and Ozmen, M. (2005). Evaluation of the toxicity and teratogenity of six commercial textile dyes using the frog embryo teratogenesis assayXenopus. Drug Chem. Toxicol. 28, 51-65

Ekpete O.A. and Horsfall M. Jnr (2011). Preparation and Characterization of Activated Carbon derived from Fluted Pumpkin Stem Waste (Telfairia occidentalis Hook F). Research Journal of Chemical Sciences. Vol. 1 (3) June 201110 - 17 
Ekpete, O. A., M. Horsfall Jnr and T. Tarawou (2011a) Adsorption of Chlorophenol from Aqueous Solution on Fluted and Commercial Activated Carbon J. Nepal Chem. Soc., vol. 27, 1- 10

Ekpete, O A; Horsfall, M Jnr; Tarawou, T (2011b). Evaluation of Activated Carbon from Fluted Pumpkin Stem Waste for Phenol and Chlorophenol Adsorption in a Fixed-Bed Micro-Column Journal of Applied Science \& Environmental Management. 15 (1), $141-146$

Fan, M., Marshall, W., Daugaard, D., Brown, R.C., (2003), Steam activation of chars produced from oat hulls and cornstover, Bioresource Technol., 93, 103-117. http://dx.doi.org/10.1016/j.biortech.2003.08.016

Gimba C, Ocholi O, Nok A. (2004). Preparation of A.C from Agricultural wastes II. Cyanide binding with activated carbon matrix from groundnut shell. Nigerian journal of scientific research. Bioresour. Technol. 97, 401-406.

Gupta, K.V., Gupta, M. and Sharma, S. (1994) Process development for the removal of lead and chromium from aqueous solution using red-mud-an aluminium industry waste. Water Research. 35(5): 1125-1134.

Ho, Y. S., McKay, G. (1998). Sorption of dye from aqueous solution by peat, Elsevier Chem. Eng. Journal. 70, (2)115-124.

HO, Y.S.; John-Wase, D.A. and Forster, C.F. (1995). Batch nickel removal from aqueous solution by sphagnum moss peat. Water Research, 29, 5, 13271332.

Horsfall, M. Jnr and Abia, A. A (2003). Sorption of Cd (II) and $\mathrm{Zn}$ (II) ions from Aqueous solutions by Cassava Waste Biomass (Manihot sculenta Cranz). Wat. Res. 37, 4913 - 4923

Horsfall, M Jnr and Spiff, A I. (2005). Effect of metal ion concentration on the biosorption of $\mathrm{Pb}^{2+}$ and $\mathrm{Cd}^{2+}$ by Caladium bicolor (wild cocoyam). 4 (2), 191-196, DOI: 10.5897/AJB2005.000-3038

Horsfall, M. Jnr., Fred E. Ogban, and E. Akporhonor (2006). Recovery of lead and cadmium ions from Metal-loaded Biomass of Wild Cocoyam (Caladium bicolor) using Acidic, Basic and Neutral Eluent Solutions. Elec. Journal of Biotechnology Vol. 9 No 2 152 - 156, 2006
Horsfall, M. Jnr and Vicente, J. L. (2007). Kinetic study of liquid phase adsorptive removal of heavy metal ions by almond tree (Terminalia catappa L.) leaves waste. Bulletin of Ethiopian Chemical Society Volume 21 (3) 249 - 262. Ethiopia

Horsfall, M. Jnr, F. E. Ogban, and E. E. Akporhonor (2005). Biosorption of $\mathrm{Pb}^{2+}$ from Aqueous Solution by Rhizophora mangle Aerial Root Waste Biomass. Chemistry \& Biodiversity Vol 2 No 9 $1246-1255$

Horsfall, M. Jnr.; and Spiff, A. I. (2005b). Sorption of Lead, Cadmium, and Zinc on Sulfur-Containing Chemically Modified Wastes of Fluted Pumpkin (Telfaria occidentalis) HOOK f.). Chem. \& Biodiversity; Vol. 2; pp 373 - 385 .

Itodo AU, Abdulrahman FW, Hassan LG, Maigandi SA, Happiness UO. (2009). Thermodynamic, equilibrium, kinetics and adsorption mechanism of industrial dye removal by chemically modified poultry droppings activated carbon. Nigerian Journal of Basic and Applied Science; 17(1):38-43.

Kadirvelu K, Palanival M, Kalpana R, Rajeshwari S, (2000). Activated carbon from an agricultural byproduct for the treatment of dyeing industry wastewater, Biores.Technol. 74 263-265.

Langergren, S (1898). About the theory of so-called adsorption of soluble substances. Kungliga svenska. Vetenskapsakademiens, Handlinger, 24 (3) $1-39$

Mohamad, R, Salmah, H and Teh, P. L. (2014). Chemical composition of Nypa fruticans filled Polylactic Acid /Recycled Low-density Polyethylene Biocomposts. BioResources 9 (2) $2033-2050$

Namasivayam, C, M.D. Kumar, K. Selvi, R.A. Begum, T. Vanathi, R.T. Yamuna (2001). Waste coir pith - a potential biomass for the treatment of dyeing wastewaters. Biomass Bioenergy, 21 pp. 477-483

Nyananyo, B. L. (2006). Plants from the Niger Delta. Onyoma Research Publications pp 290 and 387

Poots, V.J.P., G. Mackay and J.J. Healy, (1978). Removal of basic dye from effluent using wood as an adsorbent. J. Water Pollut. Control Federation, 50: $926-935$.

Qureshi K., Bhatti I., Kazi R. and Ansari A.K. (2008). Physical and chemical analysis of activated carbon 
prepared from sugarcane bagasse and use for sugar decolorisation, Inter. J. Chem. Bimolecular. Engnr., 1(3), 145- 149

Rengaraj, S., Arabindoo, B. and V. Murugesan, Preparation and characterization of activated carbon from agricultural wastes. Indian J. Chem. Tech., 6(1), 1-4 (1999).

Tarawou, T; Wankasi, D; Horsfall, M (2007). Column Removal of methylene blue using activated carbon derived from water spinach (Ipomoea aquatic) Int. J, Biol. Chem. Sci Vol 4. No 3. 535 - 545

Tarawou, T; Wankasi, D; Horsfall, M (2010a). Sorption kinetic study on the removal of basic blue-9 dye using activated carbon produced from water spinach. Int. J, Biol. Chem. Sci. 4. (3). 703 - 709

Tarawou, T; Wankasi, D; Horsfall, M. Jnr., (2010b). Sorption kinetic study on the removal of basic blue-9 dye using activated carbon produced from water spinach. Int. J. Biol. Chem. Sci Vol 4. No 3. $703-709$
Tarawou, T; Wankasi, D; Horsfall, M. Jnr., (2010c). Sorption of manganese (II) and chromium (III) ions from aqueous solution using water hyacinth biomass (Eichhornia crassipes). J. Environmental Sci. \& Engineering Vol 4. No 11.Serial No. 36.38 $-43$

Tsai W.T., Chang C.Y., Wang S.Y., Chang C.F., Chien S.F. and Sun H.F., (2001). Preparation of activated carbons from corn cob catalyzed by potassium salts and subsequent gasification with $\mathrm{CO}_{2}$, Biores. Technol.,78, 203-208

Wankasi, D., Horsfall, M. J., Spiff, A. I., (2005a). Desorption of $\mathrm{Pb}^{2+}$ and $\mathrm{Cu}^{2+}$ from Nipa palm (Nypa fruticans Wurmb) biomass. Afr. J. Biotechnol. 4, 923-927.

Wayne Boyles (1997). The Science of Chemical Oxygen Demand (COD). Technical Information Series, Booklet No. 9. Pp8-9 